\title{
THE STRUCTURAL RESPONSE OF THE PARATHYROID GLANDS TO URETERAL LIGATION OR BILATERAL NEPHRECTOMY
}

\author{
BURTON L. BAKER \\ Department of Anatomy, University of Michigan Medical School, Ann Arbor, Michigan \\ TWO PLATES (ELEVFN FIGURES)
}

In spite of the great physiological importance of the parathyroid glands, little is known concerning the part played by intra-cellular organelles in their secretory activity. It is obvious that one of the most promising approaches to the solution of this problem is to study the parathyroid cells after the secretory activity of the gland has been stimulated or depressed by experimental means. Several experimental procedures are now known which will alter the structure and function of the parathyroids but in using them, most investigators have given only minor attention to changes occurring within the parenchymal cells and have regarded the induction of hypertrophy or atrophy of the entire gland as being indicative of hyperactivity or hypoactivity, respectively. In fact, the only cytological investigations of experimentally modified parathyroids reported thus far, were those of DeRobertis, who studied the parathyroids after treatment of rats with single doses of parathyroid extract ('40) and after feeding them low ealcium or low phosphorus diets ('41).

One of the conditions which will stimulate parathyroid activity is renal insufficiency. MacCallum ('05), Bergstrand ('21), Hubbard and Wentworth ('21), Pappenheimer and Wilens ('35), Pollack and Siegal ('36), Magnus and Scott ('36), and Gilmour and Martin ('37) observed enlarged parathyroids in human chronic nephritis. Proof that accelerated secretion accompanies this enlargement was supplied by Highman and Hamilton ('37) who demonstrated that blood from twenty-three cases of chronic nephritis, when injected into rabbits under the conditions of the Hamilton and Schwartz parathyroid function test, caused a significant elevation of the serum calcium level in the recipient animals. Shelling and Remsen ('35) obtained similar results with the same technique in a case of renal rickets accompanied by marked parathyroid hyperplasia. It is believed that the modus operandi of such stimulation involves the retention of phosphate which tends to cause a reciprocal 
lowering of the serum calcium level which tendency, in turn, causes hyperplasia of the parathyroid glands (Albright, '41).

The available evidence shows that renal insufficiency stimulates the parathyroid glands in the lower animals, as well as in man. The mechanism of this stimulation seems to be similar to that in man since Winternitz et al. ('40) have shown that bilateral nephrectomy in the dog causes an early retention of phosphate and a progressive reduction in the serum calcium level to that found in tetanic states. Parathyroid hypertrophy has been reported after experimental reduction of kidney substance in rats (Pappenheimer, '36; Opper and Thale, '43) and dogs (Highman and Hamilton, '38). In more acute experiments, Selye ('42) and Ingalls et al. ('43) found bilateral nephrectomy to produce some decalcification of bone, and since Selye obtained this effect only if the parathyroids were intact, he concluded that nephrectomy stimulated them to accelerated secretory activity. Thus, renal insufficiency, as induced by ureteral ligation or bilateral nephrectomy, offers an admirable opportunity for study of the early response of the parathyroid cells to stimulation, before the picture is obscured by compensating factors such as extensive hyperplasia, or by cytological changes resulting from prolonged stimulation.

\section{MATERIAIS AND METHODS}

One hundred and seventeen male and female rats of the Long-Evans strain, ranging in age from 107 to 579 days, were used in these studies. Their diet consisted of Purina Dog Chow supplemented weekly with greens and citrus fruits. The experimental animals were subjected to bilateral nephrectomy or ureteral ligation with non-operated littermates serving as controls. Since other investigators have experienced difficulty in maintaining complete occlusion of the ureters in small animals, an attempt was made to insure this result by first grasping the ureter with a hemostat. Then, the portions of the ureter at either side of the hemostat were approximated around the end of the instrument and tied together with a double ligature of silk thread. The ureters were examined at autopsy and, in all cases, were engorged with fluid above the ligature. The rats were allowed to live for 31-74 hours post-operatively, the majority being killed at about 50 hours. This does not represent a true survival time since care was taken to sacrifice them before death. Nevertheless, all were dyspneic at autopsy and some, in extremis. In order to exclude shock as a complicating factor, a group of rats was subjected to either massage of the intestines or decapsulation of the kidneys. The damage inflicted upon these rats was similar to that which 
accompanied ureteral ligation or nephrectomy. These rats were killed 50 hours post-operatively and their parathyroids showed no cellular enlargement or increased mitotic activity and, apparently, no glandular hypertrophy as compared with the parathyroid glands of littermate controls.

The parathyroids, with some attached thyroid tissue, were fixed in Champy's, Bouin's or Regaud's fluids. Those preserved in Champy's fluid were osmicated subsequently by the Nassonov-Kolatchev method and those in Regaud's fluid were treated with $3 \%$ potassium dichromate. The following stains were employed: Harris' or Ehrlich's hematoxylin and eosin or azure II-eosin, modified Masson, Altmann-Masson as modified by Severinghaus and Thompson ('39), Mallory-Azan and Vandergrift's technique for reticulum as described by Bennett ('40). These glands were imbedded in tissuemat or in celloidin and tissuemat and sectioned at thicknesses ranging from $3 \mu$ to $6 \mu$.

The volume of the Bouin-fixed glands was calculated from planimetrically-determined areas of outline drawings of every tenth section projected at a magnification of $\times 200$. This method for determining the volume of small organs has been reported to entail considerable error and to be less accurate than the paper weight method (Scammon and Scott, '27). Recent data obtained by Dr. W. T. Dempster show that the accuracy of the planimetric method for a given shape increases in proportion to the size of the area measured. Because of his findings and in order to reduce possible error, a sufficiently high magnification was used in projecting the sections for tracing, so that the outline drawings of the largest sections measured from 10-19 cm. in diameter. In contrast, the diameter of the largest disc studied by Scammon and Scott was only $4 \mathrm{~cm}$. No search was made of the cervical and thoracic regions for accessory parathyroids. It is exceedingly doubtful whether their inclusion would have influenced significantly the difference in volume of control and experimental glands, since the accessory parathyroids in the rat have been shown to be so minute as compared with the two chief parathyroids (Erdheim, '14).

Cellular hypertrophy was determined by the indirect method of counting the number of nuclei with the aid of an oil immersion objective in systematically selected areas from $4 \mu$ central sections of the gland. In most cases, about 30 fields were examined and over 1000 nuclei counted. In order to show that cellular enlargement in the parathyroids was not a general reaction of the body cells, a cell height index was ascertained for the follicular epithelium of the thyroids in the above cases, by finding the average height of 100 cells in several central 
sections. In each section, one cell from opposite sides of every transversely-cut follicle was measured with an ocular micrometer $(\times 900)$. Mitotic activity was estimated by counting the number of mitotic figures in ten of the central sections of the Bouin-fixed glands, these having been sectioned at $4 \mu$. In so far as possible, sections of comparable size were used.

\section{OBSERVATIONS}

The normal gland. In most rats, a single spheroidal or ellipsoidal parathyroid was found partially imbedded on the antero-lateral surface of each lateral thyroid lobe near the superior pole. Occasionally, microscopic examination of serial sections of the entire thyroid failed to reveal more than one parathyroid and, in such cases, it was felt that one gland had been located in an extra-thyroidal position and was missed at autopsy. In general, the members of each pair were of similar volume, the average ratio of the volume of the large to that of the small parathyroid in the control animals being $.80 \pm$ standard deviation 0.06 as compared with the ratio of $.79 \pm$ s.d. 0.12 based on calculated weight reported by Sinclair ('41). Our determinations of the volume of the glands from these rats are closely comparable with those of Blumenfeld and Rice ('38) but are considerably less than the measurements of Pappenheimer ('36).

A thin connective tissue layer surrounded the gland and followed the larger blood vessels into the interior. For the most part, it consisted of collagenous fibers. Continuous with, and extending out from these trabeculae were finer strands of argyrophilic fibers which surrounded the closely-packed clusters and cords of parenchymal cells and encompassed narrow capillaries. Mast cells were demonstrated in the broader connective tissue trabeculae by hematoxylin and azure II-eosin and by the Masson stain.

The principal cell was the only type of parenchymal cell present, no oxyphils having been found. With the usual histological techniques no subdivision of the principal cells was possible, but mitochondria and Golgi techniques delineated scattered dark forms (figs. 5, 6). In some glands the dark cells brought out by osmication were so few as to seem insignificant; in others, they made up a large percentage of the total cell population. The pale principal cells varied considerably in size and shape. Most of them were polygonal but some of the smallest cells at the periphery of a cluster were spindle-shaped and oriented perpendicularly to the connective tissue strands. The larger cells which abutted on the connective tissue possessed a flat base and usually a dome-shaped distal (apical) end (fig. 9). 
The nuclei were usually located proximal to the connective tissue in those cells located at the periphery of the groups of parenchymal cells. Their considerable variation in form was partially accounted for by the shape of the cell, many of them being elongated to conform to the narrowness of the cell. Few were perfectly spherical, the nuclear membrane generally being folded inwards in one or two places (fig. 10). No plasmasomes were demonstrated by the stains employed but at least one karyosome could be discerned. As in man (Bergstrand, '19; Morgan, '36), the horse, (Bobeau, '11) and monkey (Cowdry and Scott, '36; Baker, '42) mitotic figures were few in the adult rat, a search of ten of the largest sections rarely revealing more than two or three. Nevertheless, they were more common than in the monkey.

Most workers have described the cytoplasm of the principal cells as being' homogeneous. This held true in preparations fixed in Regaud's or Champy's fluid but after Bouin fixation the cytoplasm was definitely reticular. However, some variation in density was evident in Champy preparations, the cytoplasm tending to be lighter in some of the larger cells. No basophilic structure resembling the juxtanuclear body of man (Pappenheimer and Wilens, '35) or monkey (Baker, '42) was found. All attempts to stain secretory precursors have failed.

The mitochondria were filamentous, usually curved, and sometimes seemed to branch (fig. 6). Their distribution was irregular, although occasionally they showed a tendency to accumulate at one end of the cell. However, this was never as marked as previously observed in the monkey. The position of the nucleus in the end of the cell proximal to the connective tissue and of the Golgi apparatus in the distal end, indicated a definite secretory polarity (fig. 8) but sufficient evidence is not yet available to establish this point. The Golgi apparatus seemed to accomodate itself to the volume of cytoplasm by variation in form. In the smallest cells, it consisted of a short filament or compact network pressed against one side of the nucleus by the cellular membrane (fig. 1). In larger cells its form was that of a long undulating filament located on one to three sides of the nucleus, or of a loose network.

As pointed out above, with the Nassonov-Kolatchev technique, variable numbers of dark principal cells could be discerned, which, because of the darkening of their cytoplasm with osmium, may best be designated as "osmiophilic" principal cells (fig. 5). It is necessary to give considerable attention to the nature of this cell because of the great importance attached to it in secretory processes by Rosof ('34) and DeRobertis ('40, '41), the former designating at least some of the osmiophilic material as intra-cellular secretion, and the latter finding an 
increase in number of these cells in animals fed on low calcium or low phosphorus diets. The osmiophilic cell seemed to arise as a transformation of the larger pale principal cells gradually becoming in this process, a smaller cell with an indistinct membrane. The first evident change was a slight darkening of the cytoplasm which appeared gray in non-stained Nassonov-Kolatchev preparations (fig. 3). In these cells, the black Golgi apparatus was differentiated clearly from the cytoplasm (figs. 3 and 4) and rarely showed evidence of becoming dispersed throughout the cytoplasm in association with vacuoles as described by DeRobertis ('40). In some cells it was fragmented. As the osmiophilia of the cell increased, the cytoplasmic structure in many cells seemed reticular and, ultimately, appeared to show some vacuolation. The Golgi apparatus remained close to the nucleus and, finally, became indistinguishable in the general blackening of the cytoplasm. Coincidently with these changes, the nuclear membrane became osmiophilic (fig. 4), wrinkled with marked infolding's (fig. 5) and, in some instances, frankly lobated. Many of these cells were spindle-shaped with little cytoplasm.

Osmiophilic cells could not be demonstrated with absolute certainty by other techniques. However, in Regaud preparations, sparsely scattered dark cells occurred which showed all stages of transition from the larger pale principal cells. Several characteristics suggested that they might be related to the osmiophilic cell just described. The darkest ones were small, stellate or spindle-shaped with dark cytoplasm and, like many of the osmiophilic cells, showed a reduction in the percentage volume of the cytoplasm in relation to the nucleus (fig. 6). The nucleus was dark. Mitochondria were present and, although not particularly numerous, were in some instances more brilliantly stained and thicker than those of the other principal cells. Since these cells were scattered singly throughout the larger glands, it was assumed that they represented a definite state of cellular activity, although they might easily be confused with small dark cells at the free surface of the gland which have been believed to result from drying or compression of the parathyroid in the rat (Jackson, '16), man (Gilmour, '39) and monkey (Baker, '42).

The effects of nephrectomy or ureteral ligation. The average absolute volume of the parathyroids was increased $28 \%$ by ureteral ligation and $32 \%$ by nephrectomy (table 1 ). Calculated on the basis of cubic millimeters of parathyroid per $100 \mathrm{gm}$. of body weight, the mean volume of the parathyroids from rats subjected to ureteral ligation was $0.09 \pm$ s.d. $0.014 \mathrm{cu}$. mm. as contrasted to $0.065 \pm \mathrm{s} . \mathrm{d} .0 .012 \mathrm{cu}$. $\mathrm{mm}$. for the parathyroids from control rats. After nephrectomy, the mean volume was 
$0.098 \pm$ s.d. $0.017 \mathrm{cu} . \mathrm{mm}$. as contrasted to $.074 \pm$ s.d. $0.010 \mathrm{cu}$. mm. for the controls. This enlargement resulted from both hypertrophy and hyperplasia of cells. There was a reduction in the number of nuclei counted per unit area of $16.3 \%$ in females and $17.5 \%$ in males which clearly indicates cellular hypertrophy (table 2). This conclusion is verified further by comparison of figures 8 and 9 , and 10 and 11. In extreme cases, almost all cells seemed to be affected; in others, only a small percentage. Proof that cellular enlargement was not a general reaction of the body cells was derived from two sources. Measurement

TABLE 1

The effect of ureteral ligation and nephrectomy on the volume of the parathyroids of adult male rats.

\begin{tabular}{|c|c|c|c|c|}
\hline TRFATMENT & $\begin{array}{l}\text { No. } \\
\text { RATS }\end{array}$ & $\begin{array}{c}\text { NO. } \\
\text { PARA- } \\
\text { THYROIDS }\end{array}$ & $\begin{array}{l}\text { MEAN ABSOLUTR VOLUME } \\
\text { PER RAT (CU. MM.) }\end{array}$ & $\begin{array}{c}\text { MEAN VOLUME PER } \\
100 \text { GM. } \\
\text { BODY WT. (CU. MM.) }\end{array}$ \\
\hline \multicolumn{5}{|l|}{ Ureteral } \\
\hline ligation & 12 & 22 & $.279(.187-.540)$ & $.090 \pm 0.014^{1}$ \\
\hline Controls & 11 & 18 & $.218(.159-.328)$ & $.065 \pm 0.012$ \\
\hline Nephrectomy & 8 & 16 & $.273(.210-.417)$ & $.098 \pm 0.017$ \\
\hline Controls & 9 & 18 & $.215(.159-.328)$ & $.074 \pm 0.010$ \\
\hline
\end{tabular}

${ }^{1}$ Standard deviation.

TABLE 2

The effect of ureteral ligation and nephrectomy on the size of cells.

\begin{tabular}{|c|c|c|c|}
\hline & $\begin{array}{c}\text { No. } \\
\text { RATS }\end{array}$ & $\begin{array}{l}\text { PARATHYROIDS } \\
\text { MEAN NO. NUCLEI } \\
\text { PER UNIT AREA }\end{array}$ & $\begin{array}{l}\text { THYROIDS } \\
\text { MEAN HEIGHT } \\
\text { (MICRA) }\end{array}$ \\
\hline \multicolumn{4}{|l|}{ Females } \\
\hline Experimentals & 11 & 34.3 & 9.0 \\
\hline Controls & 7 & 41.0 & 10.52 \\
\hline \multicolumn{4}{|l|}{ Males } \\
\hline Experimentals & 14 & 32.8 & 9.27 \\
\hline Controls & 7 & 39.8 & 11.49 \\
\hline
\end{tabular}

of the height of the thyroid epithelial cells showed a reverse change in both sexes, the epithelium being lower after the operations (table 2). Also, data obtained from differential cell counts on the anterior hypophyses of these animals showed no significant difference in the number of nuclei counted per field in the control and experimental animals (Leek, unpublished). Both operations caused an acceleration of mitotic activity. The average number of mitoses counted per section in the control glands was 0.18 (range of 0 to 0.7 ). Following ureteral ligation the average was 1.8 ( 0 to 5.7) and after nephrectomy, 8.2 (0.4 to 23.7). This stimulation occurred in all nephrectomized animals and in well over 
$70 \%$ of those with ligated ureters. Thus, from the standpoint of magnitude and regularity of response, nephrectomy seems to be the more potent means of inducing hyperplasia.

The Golgi apparatus was enlarged and markedly altered in form (figs. $1,2 ; 8,9)$. As was true of the other changes described, the number of cells showing this alteration varied in different animals, in some practically all cells seeming to be affected (fig. 9). This organelle, in most cases, tended to collect at one side of the nucleus and to form a large network more spherical in shape than in the controls (fig. 2). The portion of the cell enclosed by the Golgi net darkened somewhat upon osmication but not as intensely as the rest of the organelle. Osmiophilic cells did not increase and may have been reduced in number.

Many eells showed a striking increase in the number of mitochondria which tended to aggregate in the region of the Golgi apparatus (figs. 6, 7). In occasional elongated cells they seemed to be somewhat linearly arranged but this was not, as a rule, particularly noticeable. In some cases, the mitochondria seemed larger and more darkly stained. Of all the structural changes which occurred in renal insufficiency, those pertaining to the mitochondria were probably the least consistent.

Most of the nuclei enlarged and became more spherical in shape (figs. $10,11)$ thus eliminating many of the folds in the nuclear membrane. With the increase in nucleoplasm, the chromatin net became more dispersed giving the nucleus a lighter appearance. No definite nucleolar enlargement could be discerned.

In view of the abundant evidence which shows that the parathyroids are larger in females than in males (Jackson, '16; Pappenheimer and Wilens, '35; Gilmour and Martin, '37; Blumenfeld and Rice, '38), it is of interest that sex did not seem to modify significantly the response of parathyroids to renal insufficiency. Although the volumetric determinations were done only on parathyroids from male animals, the presence of cellular bypertrophy and hyperplasia in those from females indicated that they, too, were enlarged. The changes in the Golgi apparatus occurred in both sexes. Mitochondria were studied in males only. Further, our observations do not suggest any clear-cut differences between the effects of the two types of operations, except in the induction of hyperplasia, showing that the presence of renal tissue is not essential to the stimulation of parathyroids under such conditions.

No significant change was observed in the vascularity of the glands or in the connective tissue. 
The comparative rôles of cellular hypertrophy and hyperplasia in the enlargement of parathyroid glands induced experimentally or by disease, have never been defined clearly. In the present study, in which glandular enlargement was effected within the comparatively brief period of about 50 hours, cellular hypertrophy was observed in the majority of cases. Since, a few of the parathyroids possessed enlarged cells without a noticeable increase in mitotic activity, it is believed that the first response of the cells is one of hypertrophy followed, or later, accompanied by hyperplasia. In view of these findings, one is impressed by the many reports in the clinical and experimental literature of enlarged parathyroids composed of cells of normal size and showing no increase in mitotic activity. Thus, in the enlarged parathyroids of human rickets, Minor and Pappenheimer ('21) found no mitoses or cellular hypertrophy. Naintenance of rats on low calcium diets (Luce, '23) and injection of phosphate into rabbits (Drake et al., '37) led to similar results. DeRobertis ('41) observed some cellular hypertrophy but no increase in mitoses in the parathyroid cells of rats fed low calcium or low phosphorus diets. In the parathyroids of human renal insufficiency (Magnus and Scott, '36; Castleman and Mallory, '37) or experimental kidney deficiency in rats (Pappenheimer, '36) and dogs (Highman and Hamilton, '38), few or no mitoses were reported and, when studied in the human cases, the cells were believed to be of normal size. Consequently, hyperplasia has been given as the cause of parathyroid enlargement in many cases in which it was impossible to demonstrate heightened mitotic activity.

This frequent failure to find cellular hypertrophy and active hyperplasia in enlarged parathyroids strongly suggests that the parathyroid cells will enlarge and divide in response to stimulation until a sufficient number of secreting units is obtained to meet the increased demand, at which time they then revert to their normal size and state of divisional activity. Thus, it appears that an equilibrium exists between the stimulating factor (low serum calcium?) and the secretory power of the gland, and that whenever the mass of parathyroid tissue is unable to meet increased bodily demands further hyperplasia and glandular enlargement will ensue. The operation of this relationship between the parathyroids and the serum calcium level may, in some respects, resemble that between the thyroid and blood iodine as outlined by Marine ('35). 
Tn line with the findings of the present study are the reports that both cellular hypertrophy and increased mitotic activity occur in the parathyroids of rats in spontaneous rickets (Erdheim, '14) and after bone fractures (Nakamura and Oka, '33). The induction of these chang'es in the parathyroids of the rat by nephrectomy stands in contrast to the failure of Winternitz et al. ('40) to find any evidence of cell division or hyperplasia in the parathyroids of dogs subjected to bilateral nephrectomy.

The marked increase in the number of mitochondria observed in the pale forms of principal cells is of particular significance. Some years ago, Kingsbury ('12) pointed out that mitochondria seem to play a part in productive processes, such as secretion, which involve oxidationreduction phenomena. More recently, they have been associated with secretory processes in studies of numerous glands by many investigators. In the chemistry of mitochondria is found a sound basis for the belief that an increase in their number may be associated with the augmented capacity of a cell to carry out whatever enzymatic reactions may be involved in the synthesis of secretion. Thus, mitochondria contain glutathione and vitamin A (Joyet-Lavergne, '35), the succinoxidase system, cytochrome oxidase, and will oxidize glutamic acid and catalyze the decomposition of hydrogen peroxide (Lazarow and Barron, '41; Bensley, '43).

Many cytologists regard the Golgi apparatus as being directly involved in the production of secretion by glạndular cells and associate enlargement of this structure with accelerated production of secretion (Kirkman and Severinghaus, '38). Hypertrophy of the Golgi apparatus was demonstrated clearly in these experiments, but its change in form demands further consideration. In parathyroids from rats with low calcium or low phosphorus rickets, DeRobertis ('41) observed the Golgi apparatus to become widely spread throughout the cytoplasm and associated with bleb-like formations in some cells. Since the same or a similar stimulating mechanism is presumably at work in renal insufficiency, it was expected that the same cytological changes would occur after ureteral ligation or nephrectomy. On the contrary, although the Golgi apparatus was enlarged considerably, it did not spread throughout the cytoplasm but became localized and rounded up at one side of the nucleus. There might be two explanations for this discrepancy : (1) technical variations and (2) the possibility that factors other than low serum calcium act to modify the response of the parathyroids to renal insufficiency. The relative significance of these explanations cannot be evaluated at present. 
Of prime importance in a cytological analysis of the response of the parathyroid glands to renal insufficiency, is the failure of our specimens to show an increase in the number of osmiophilic cells. This is of particular interest because DeRobertis ('40) found them to be reduced in number in the hypoactive state brought about by the injection of single doses of parathyroid extract. Conversely, he found the osmiophilic cells to be increased under the stimulating influence of low calcium or low phosphorus diets ('41). Previously Rosof ('34) had regarded at least some of the osmiophilic material in these cells as secretion. Although DeRobertis considered the osmiophilic cells to represent a phase in the secretory activity of the parenchymal cells, he did not interpret the osmiophilic material as being secretion.

Indeed, there are several criticisms which may be raised against Rosof's conclusion that the osmiophilic cells are the actively secreting cells of the parathyroid gland. First, Rosof described an intricate interrelationship of Golgi apparatus, mitochondria and secretory substance in which osmiophilic droplets of secretion appeared at the ends of long parallel strands formed by junction of projections of the Golgi apparatus with mitochondria. The present preparations do not duplicate this picture, but in them osmiophilia seems to be a reaction of the general cytoplasm and the material giving this reaction cannot be identified as either Golgi apparatus or mitochondria. When still distinguishable during the early development of the cell, the Golgi apparatus is small and not dispersed throughout the cytoplasm. Second, the cell seems to become smaller as the osmiophilic reaction increases in intensity, some of the darkest cells being comparatively small. In these, the volume of cytoplasm in proportion to nucleus is markedly less than in the larger pale forms. If the blackened substance is secretion, one might expect the cell to enlarge as secretion accumulates within it. Third, the nuclear structure is not one commonly associated with normal glandular cells in a state of high secretory activity. Critical osmication of glandular cells rarely blackens the nuclear membrane but this occurs in the osmiophilic cell. This reaction has been observed previously in my work only in certain cells at the center of trophoblastic cell islands of the human placenta where the presence of an active degeneration at the stages studied hardly can be doubted (Baker et al., '44). The occasional lobation of the nucleus could be interpreted in terms of loss of vitality by the cell. Fourth, chemical analyses of the parathyroid hormone indicate that it is protein in nature (Ross and Wood, '42). Although intensive osmication may blacken protein, generally this does not occur if the process is carefully controlled. It is true that some other secre- 
tions derived from amino acids may possess considerable reducing power, yet on the basis of our present inadequate knowledge of the chemical structure of the parathyroid hormone, there is little foundation for believing that this material within the cell would be strongly osmiophilic.

Therefore, it would seem that more supporting evidence must be presented before the osmiophilic cells may be regarded as the actively secreting units of the parathyroid gland. It might be prudent to view these cells, at least temporarily, as representing a state of secretory exhaustion. This would explain why they did not accumulate after nephrectomy or ureteral ligation but did in animals maintained on a low calcium or low phosphorus diet (DeRobertis, '41). Whereas, in the present experiments the stimulating influence was effective for only a portion of the average survival time of 50 hours, the animals of DeRobertis were maintained on the experimental diets for 4 weeks. Thus, in his rats many of the parathyroid cells may have been worn out by long-continued stimulation. If osmiophilic cells are the only ones which release parathyroid hormone, it would be impossible to account for an increased secretion of hormone in rats subjected to acute renal insufficiency. Consequently, the results of these experiments lead one to regard the large, more numerous pale forms as being the hormoneproducing elements since significant cytological modifications occurred in them.

The structural changes observed in this study, namely, glandular, cellular and nuclear enlargement, hyperplasia, enlargement of the Golgi apparatus and increase in number of mitochondria, can all be interpreted in terms of stimulation. Therefore, they support and supplement each other.

\section{SUMMARY}

The parathyroid glands of rats responded to acute renal insufficiency, as induced by ureteral ligation or bilateral nephrectomy, with the following structural modifications: (1) nuclear and cellular hypertrophy and hyperplasia leading to enlargement of the gland as a whole, (2) hypertrophy and alteration in form of the Golgi apparatus in the pale principal cells and (3) increase in the number of mitochondria in these cells. There was no increase in number of osmiophilic cells or alteration in vascularity. These changes were largely independent of sex or the presence of renal tissue, with the exception that nephrectomy was more effective than ureteral ligation in the induction of hyperplasia. 


\section{LITERATURE CITED}

Albright, F. 1941 The parathyroids - physiology and therapeuties. J. Am. Med. Assoc., vol. 117 , p. 527 .

BAKER, B. L. 1942 A study of the parathyroid glands of the normal and hypophysectomized monkey (Macaca mulatta). Anat Rec., vol. 83, p. 47.

BaKer, B. L., S. J. Hook AND A. E. Severinghaus 1944 The cytological structure of the human chorionic villus and decidua parietalis. Am. J. Anat., vol. 74, p. 291.

BenNeTT, H. S. 1940 The life history and secretion of the cells of the adrenal cortex of the eat. Am. J. Anat., vol. 67, p. 151.

Bensley, R. R. 1943 Chemical strueture of eytoplasm. Biological Symposia, vol. X. Jaeques Cattell Press, Lancaster, Pa.

Bergstrand, H. 1919 Parathyreoideastudien I. Zur normalen Anatomie der Glandula para thyreoidea. Acta Med. Scand., Bd. 52, S. 791.

1921 Parathyreoideastudien II. Über Tumoren und hyperplastische Zustände der Nebenschildrüsen. Acta Med. Seand., Bd. 54, S. 539.

BLumenfeld, C. M., And H. M. Rice 1938 The volume of the parathyroid glands of the albino rat. Anat. Rec., vol. 70, p. 227.

BoBeav, G. 1911 Sur les glandules parathyroĬdes du cheval. J. d. l'Anat. et Physiol., T. 47, p. 371.

Castleman, B., and T. B. Maldory 1937 Parathyroid hyperplasia in chronic renal insufficiency. Am. J. Path., vol. 13, p. 553.

Cowpry, E. V., AND G. H. SCOT' 1936 Effect on monkeys of small doses of a concentrated preparation of viosterol. Arch. Path., vol. 22, p. 1.

DeRoBertis, F. 1940 The cytology of the parathyroid gland of rats injected with parathyroid extract. Anat. Rec., vol. 78, p. 473.

194.1 The eytology of the parathyroid and thyroid glands of rats with experimental rickets. Anat. Rec., vol. 79, p. 417.

Drake, T. G., F. Albright and B. Castleman 1937 Parathyroid hyperplasia in rabbits produced by parenteral phosphate administration. J. Clin. Invest., vol, 16, p. 203.

Erdheim, J. 1914 Rachitis und Epithelkörperchen. Math-Naturwiss. Kl. d. Kais. Akad. d. Wiss. Wien.

Gilmour, J. R. 1939 The normal histology of the parathyroid glands. J. Path. and Bact., vol. 48 , p. 187.

Gilmour, J. R., AND W. J. MARTin 1937 The weight of the parathyroid glands. J. Path. and Bact., vol. 44, p. 431

Highman, W. J., and B. Hamilton 1937 Hyperparathyroidism in kidney disease. J. Clin. Invest., vol. $16, \mathrm{p} .103$.

1938 Hyperparathyroidism secondary to experimental renal insufficiency. Arch. Path., vol, 26, p. 1029.

HubBard, R. S., AND J. A. WentworTh 1921 A case of metastatic caleification associated with chronie nephritis and hyperplasia of the parathyroid glands. Proc. Soc. Exp. Biol. and Med., vol. 18, p. 307.

IngALLS, T. H., G. Donaldson AND F. Albright 1943 The locus of action of the parathyroid hormone: experimental studies with parathyroid extract on normal and nephrectomized rats. J. Clin. Invest., vol. 22, p. 603.

JACKSON, C. M. 1916 Effects of inanition upon the structure of the thyroid and the parathyroid glands of the albino rat. Am. J. Anat., vol. 19, p. 30 .

Joyet-Lavergne, P. 1935 Recherches sur la catalyse des oxydo-reductions dans la cellule vivant. Protoplasma, T. 23, p. 50.

Kingsbury, B. F. 1912 Cytoplasmic fixation. Anat. Rec., vol. 6, p. 39.

Kirkman, H., AND A. F. Sevfringhaus 1938 A review of the Golgi apparatus. Part III. Anat. Ree., vol, 71, p. 79 . 
LAZAROW, A., AND E. S. G. BARRON 1941 The oxygen uptake of mitochondria and other cell fragments. Anat. Rec., suppl. p. 41.

LuCE, E. M. 1923 The size of the parathyroids of rats, and the effect of a diet deficiency of calcium. J. Path. and Bact., vol. 26, p. 200.

MacCaldum, W. G. 1905 Tumor of the parathyroid gland. Bull. Johns Hopkins Hospital, vol. 16, p. 87.

Magnus, H. A., AND R. B. ScotT 1936 Chronic renal destruction and parathyroid hyperplasia. J. Path. and Bact., vol. 42, p. 665.

Marine, D. 1935 The pathogenesis and prevention of simple or endemic goiter. Gland. Physiol. and Therapy., Am. Med. Assoc., Chicago, IIl.

Minor, J., ANd A. M. PAPPenheimer 1921 Hyperplasia of the parathyroid glands in rickets. Proc. N. Y. Path. Soc., vol. 21, p. 98.

Morgns, J. R. E. 1936 The parathyroid glands I. A study of the normal gland. Arch. Path., vol. 21 , p. 10 .

Nakamura, T., AND J. OKa 1933 Über die Veränderungen der Sehildarüse und der Epithelkörperchen bei Knochenfrakturen. Trans. Soe. path. jap., Bd. 23, S. 102.

OPPER, L., AND T. THALE 1943 The influence of pregnancy, hyper-vitaminosis-D and partial nephrectomy on the volume of the parathyroid glands in rats. Am. J. Physiol., vol. 139 , p. 406.

Pappenmeimer, A. M. 1936 The effect of experimental reduction of kidney substance upon the parathyroid glands and skeletal tissue. J. Exp. Med., vol. 64, p. 965.

PAPPEnhetmer, A. M.,AND S. L. Wilens 1935 Enlargement of the parathyroid glands in renal dicease. Am. J. Path., vol. 11, p. 73.

Poldack, H., And S. SIEgaL 1936 Parathyroid hyperplasia and calcinosis associated with renal disease. J. Mount Sinai Hospital, vol. 2, p. 270.

RosoF, J. A. 1934 An experimental study of the histology and eytology of the paratiyroid glands in the albino rat. J. Exp. Zool., vol. 68, p. 121.

Ross, W. F., AND T. R. WOOD 1942 The partial purification and some observations on the nature of the parathyroid hormone. J. Biol. Chem., vol. 146, p. 49.

SCAmMon, R. E., AND G. H. SCOT⿰ 1927 The teclinique of determining irregular areas in morphological studies. Anat. Rec., vol. 35, p. 269.

SELYE, H. 1942 Mechanism of parathyroid hormone action. Arch. Path., vol, 34, p. 625.

Severinghaus, A. E., AND K. W. Thompson 1939 Cytological changes induced in the hypophysis by the prolonged administration of pituitary extract. Am. J. Path., vol. 15, p. 391 .

Sinclatr, J. G. 1.941 Size of the parathyroid glands of albino rats as affected by pregnancy and controlled diets. Anat. Rec., vol. 80, p. 479.

Shelling, D. H., AND D. REMsen 1935 Renal rickets. Report of a case showing four enlarged parathyroids and evidence of parathyroid hypersecretion. Bull. Johns Hopkins Hospital, vol. 57 , p. 158.

Winternitz, M. C., E. Mylon, L. L. Waters and R. Katzenstein 1940 Studies on the relation of the kidney to cardiovascular disease. Yale Jour. Biol. and Med., vol. 12, p. 623 . 
PLATES 


\section{PLATE 1}

\section{EXPLANATION OF FIGURES}

In figures 1-7 the outlines of the cells, nuclei and Golgi apparatuses were drawn with the aid of a camera lucida.

1 Three forms of the Golgi apparatus in normal pale principal cells: extensive undulating filament at the left, a loose spheroidal network at the right and a flat network capping the nucleus above. Female; Nassonov-Kolatehev; $3 \mu$; magnification approximately $\times 2500$.

2 In this parathyroid cell, 54 hours after ureteral ligation, the Golgi apparatus is rounded up and is located entirely at the apical side of the nueleus. Note the less osmiophilie interior of the Golgi body. Nassonov-Kolatchev; $3 \mu$; magnification approximately $\times 2500$.

3,4 and 5 Three apparently suceessive stages in the development of the osmiophilic cell. In contrast to the normal cells of figure $\mathbf{1}$, the cell of figure 3 shows a slight but general darkening of the cytoplasm. In figure 4, the cytoplasm is blacker and less homogeneous, the small Golgi apparatus is still distinet, the nuclear membrane is beginning to wrinkle and is osmiophilie. In figure 5, the slightly vacuolated eytoplasm is so dark that the Golgi apparatus is indistinguishable, the nucleus shows a tendency toward lobation and the cellular membrane is indistinct. Control female; Nassonov-Kolatchev; $3 \mu$; magnification approximately $\times 2500$.

6 Palo principal cells, showing sparsely distributed filamentous mitochondria. One dark cell is at the center and shows a relative reduction in cytoplasmic volume and darkening of cytoplasm and nucleus. Below the nucleus are clear channels which are probably the negative Golgi image. Control for animal of figure 7. Regaud; Altmann-Masson; $3 \mu$; approximately $\times 2900$.

7 Pale principal cells showing hypertrophy of cells and nuclei with an increase in number of mitochondria, 54 hours after ureteral ligation. Technique and magnification same as for figure 6 . 

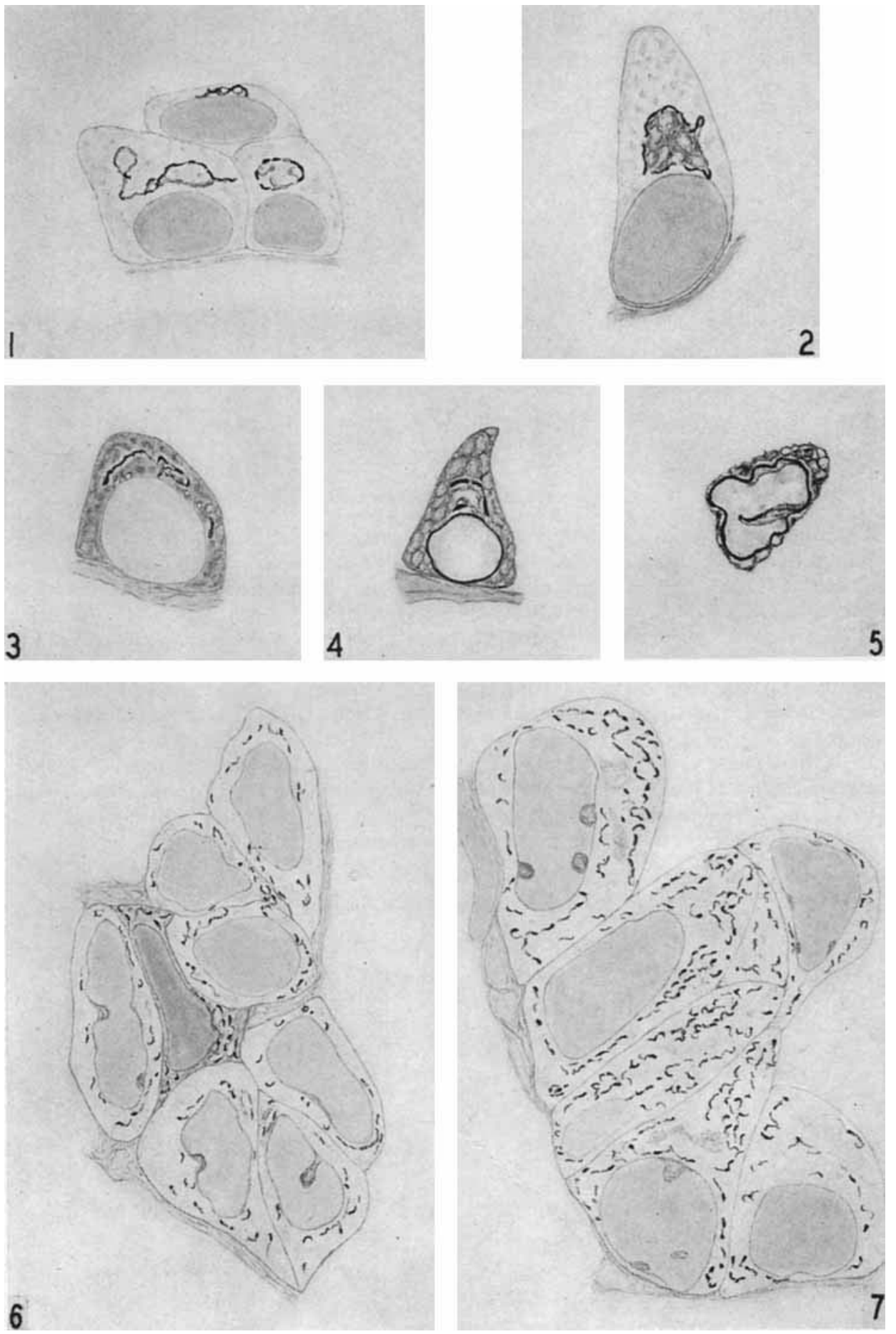
PLATE 2

EXPLANATION OF FIGURES

8 Parathyroid of control showing small black Golgi apparatuses throughout the field, closely applied to the nuclei. Vertically placed at the left is a connective tissue trabecula. The cells to the right of it show typical polarization with nuelei next to the connective tissue and Golgi apparatus distally placed. Nassonov-Kolatchev; $3 \mu ; \times 1160$.

9 Littermate of above control animal, 54 hours after ureteral ligation. Cells, nuclei and Golgi apparatuses are enlarged. Nassonov-Kolatchev; $3 \mu ; \times 1160$.

10 Parathyroid from a control male showing the irregular shape of nuclei with some tendency toward wrinkling of the nuclear membrane. Bouin; Harris' hematoxylin and eosin; $4 \mu ; \times 840$.

11 Littermate of above rat 54 hours after ureteral ligation. Cytoplasmic volume is greater; nuclei are larger and tend to be more spherical. Enlargement of nucleoli is questionable. Bouin; Harris' hematoxylin and eosin; $4 \mu ; \times 840$. 

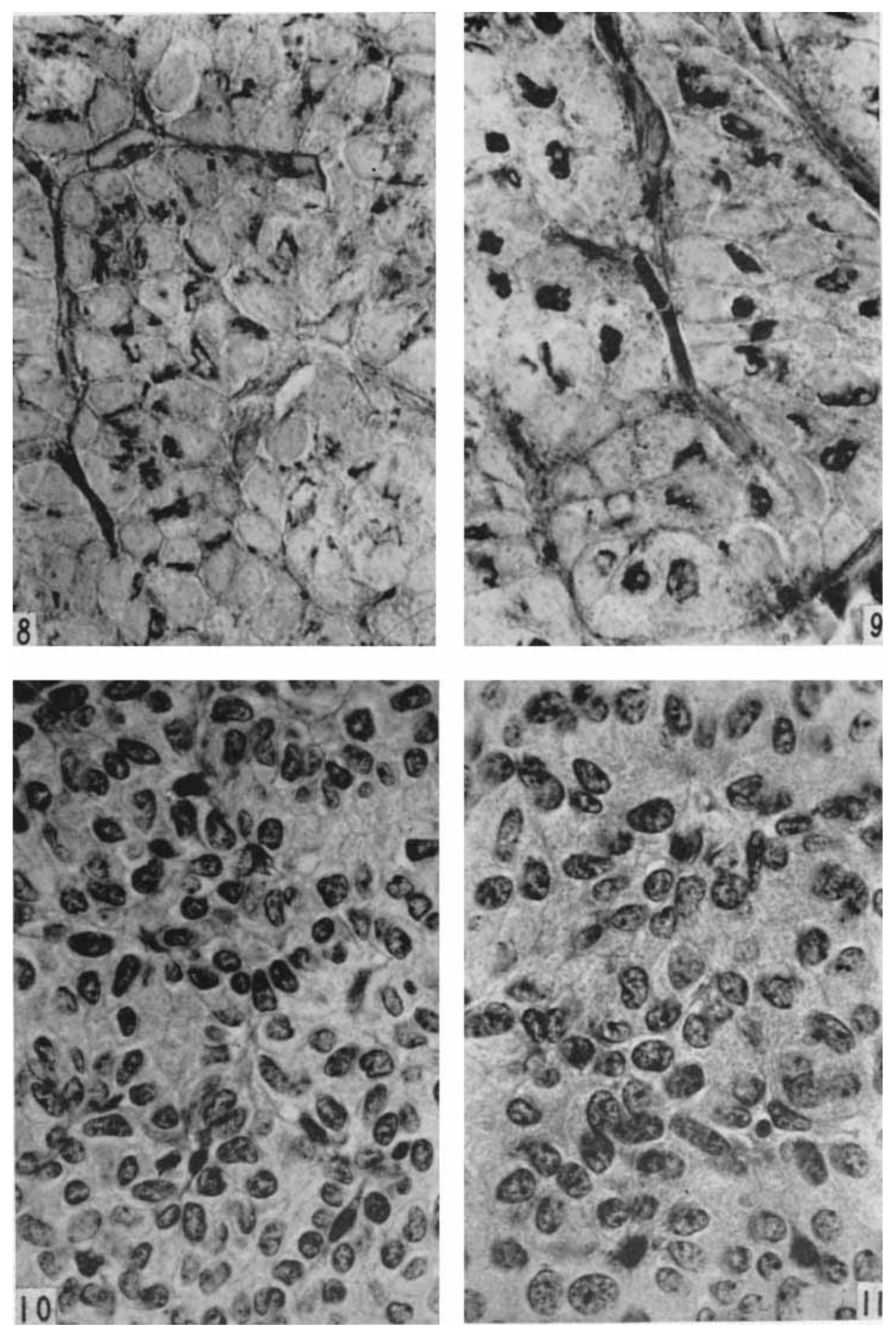